\title{
Bias alleged in Japanese university awards
}

Tokyo. A new programme that injects much needed support into research in Japan's universities, but uses a hierarchy of committees rather than conventional peer review to select project leaders, appears to have favoured institutions and individuals represented on the programme's selection committees, in particular Tokyo University.

The programme, 'Research for the Future', was launched this year by the Japan Society for the Promotion of Science (JSPS) with an initial budget of $¥ 11$ billion (US $\$ 100$ million) from the Ministry of Education, Science, Sports and Culture (Monbusho). It will support research projects for five years with an average annual budget of about $¥ 100$ million (US\$1 million) each.

The awards are particularly attractive because they are much more flexible than the traditional grants awarded by the ministry and can, for example, be used to employ postdoctoral fellows. Furthermore, in a first for science in Japan, as the programme is funded as 'capital investment', it is free from the ceilings that normally restrict growth in science budgets, and is already expected to double in size next year (sce Nature 383, 206; 1996)

But, unlike the ministry's existing grant schemes, the project grants are not awarded through open, peer-reviewed competition. Rather, project leaders are chosen in a 'topdown' fashion using a hierarchy of committees. Under this system, a top programme committee of 14 members, headed by Hiroyuki Yoshikawa, president of Tokyo University, and comprised of university presidents, directors of Monbusho institutes, and two industrialists set up three subcommittees in the fields of science and engineering, life science, and interdisciplinary research respectively.

These in turn selected 17 specialist research areas for funding on the basis of suggestions from university researchers throughout Japan, and chose the members of the selection committees for each area. The selection committees then decided who the leaders of specific research projects should be. There was no open call for university researchers to make detailed grant proposals, and no peer review.

The first 117 projects selected this summer appear to show clear signs of bias in favour of selection committee members and their institutions. In particular, Tokyo University, which was by far the most strongly represented university on the selection committees, has more than twice as many leaders of projects as any other university. Furthermore, 34 out of 98 of the selection committee members were themselves chosen to head projects that received funding.

The results are "completely outrageous", says one professor at Kyoto University who has seen the complete list of project leaders and selection committee members. He says, for example, that in genome research, four out of five project leaders are either members of the selection committee, or junior staff on the faculty of committee members.

The bias is particularly strong in science and engineering, where Tokyo University has 10 out of 41 project leaders, or 25 per cent of the awards (compared with 19 per cent for the programme as a whole, already

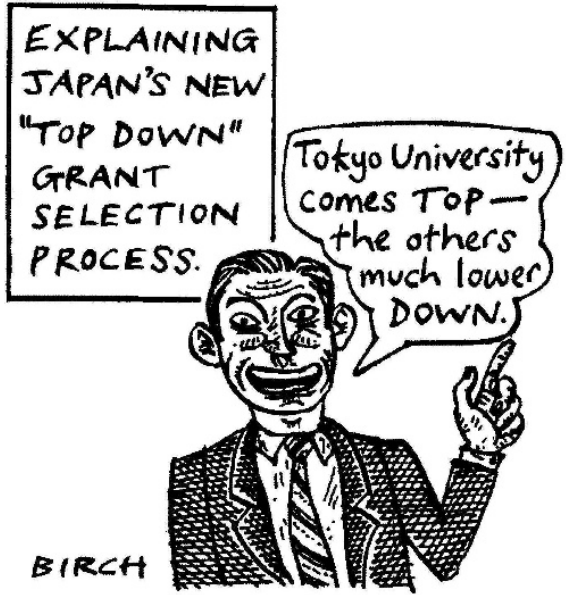

a relatively high figure). Furthermore, in this field an unusually large number of members of the selection committees - 15 - were chosen as project leaders.

According to a spokesman for JSPS, Yoshikawa played a key role in selecting the members of the science and engineering subcommittee, while Hiroo Imura, president of Kyoto University, was in charge of life sciences, and Leo Esaki, president of Tsukuba University, handled interdisciplinary research. According to one member of the top programme committee, these subcommittees were "critical" in determining the selection of research areas

\section{French scientists rally against racist claim}

Paris. More than 600 French scientists and historians have signed a statement censuring Jean-Marie Le Pen, the leader of the extreme right-wing party the National Front, for his statement of belief in the "inequality of races". Le Pen said: "It is obvious, the whole of history demonstrates it. They don't have the same capacity for evolution."

Le Pen, who obtained 15 per cent of the votes in last year's presidential election, has also made much of the fact that blacks won more medals than whites at the recent Olympic games.

The statement drafted by Albert Jacquard, a retired geneticist, contests Le Pen's claims "in the name of scientific rigour". The text says that although all humans (except identical twins) have and selection committee members.

A quarter of such committee members in science and engineering came from Tokyo University - more than three times as many as any other national university - and there were also several former professors of Tokyo University on the committees who now work at private universities but maintain strong links with Japan's leading national university.

Yoshikawa denies influencing the decisions of the selection committees. "We made a strong request that the selection committees should select the best research groups, regardless of geographical location or university," he says. But, he adds, despite a rule that committees should not select their own members, "unfortunately some one or two - could not follow this rule".

Yoshikawa says that the new 'top-down' approach of grant selection is intended to complement the traditional peer review system, which still covers 90 per cent of the university research grants awarded by the ministry of education.

He says that in the peer review system in Japan, selection committees have no responsibility for their decisions, and that he wants to introduce more responsibility and accountability. Yoshikawa says that a committee will be set up not only to review the progress of the research projects, but also to assess the selection committees themselves. If any committees are found to be "failing" in their selection of project leaders, he adds, "they will be changed".

In defence of this year's selections, Yoshikawa points out that the selection process was extremely rushed because a law allowing the new programme to be set up was not passed by the Diet, Japan's parliament, until the end of May.

David Swinbanks

different genomes, this is "in no way synonymous with hierarchy".

Populations of Homo sapiens have not been isolated for sufficiently long to have given rise to distinct races, says the text. But a columnist for the newspaper Le Monde warns that scientists may be playing into Le Pen's hands. "Arguing about the diversity of races, in the name of scientific rigour, to prove the equality of men, is to admit that this equality can be a subject of discussion," the columnist writes.

Signatories include the leading genome scientists Jean Weissenbach and Charles Auffray, the geneticist Axel Kahn, and the eminent biologists Pierre Chambon and Jean-Pierre Changeux.

Declan Butler 